\title{
FDA, researchers consider first transgenic fish
}

Officials at the US Food and Drug Administration (FDA; Rockville, MD) are currently reviewing an application from marine biotechnology firm A/F Protein (Waltham, MA) for genetically modified (GM) salmon. If approved, the transgenic fish, which have been engineered to grow faster and consume less food than their wild counterparts, will be the first to reach the marketplace. However, an FDA-funded study suggests that transgenic fish could destroy wild populations, and some scientists are skeptical about their future because of ecological concerns.

While vitamin-packed fish is still several years away, GM salmon are already being produced to address the problem of waste from farm-raised fish-something that has become an issue for coastal communities in New England and the Pacific Northwest concerned about the impacts of aquaculture.

$\mathrm{A} / \mathrm{F}$ researchers have taken a gene promoter from the ocean pout and inserted it into the Atlantic salmon, causing it to express growth hormone from its liver, as well as its pituitary gland where the hormone is normally produced. As a result, the fish grows faster and eats less, says A/F Protein CEO Elliot Entis.

A/F's GM salmon, which are bred at its experimental facility in Prince Edward Island, Canada, grow from an egg to $8 \mathrm{lbs}$ in only 14 to 18 months, half the normal time. At one year, they are 4 to 6 times larger than a normal fish of the same age. Entis insists his GM fish are no larger than normal ones at adulthood, however they reach that stage much more quickly and consume 20-25\% less food. "Our fish don't produce anything that the wild type doesn't produce."

However, researchers at Purdue University (West Lafayette, IN) have found transgenic fish don't live as long, and have published a study recently finding that GM fish could pass on this negative trait and quickly eradicate wild fish stocks (PNAS, Nov 1999).

During the FDA-funded study, William Muir and Richard Howard found that laboratory fish called the Japanese medaka (Oryzias latipes) that were genetically modified to produce human growth hormone matured faster and carried more eggs than non-GM relatives. Male individuals, because of their larger size for their age, attracted four times as many mates as smaller rivals. However, only two-thirds of GM medaka survived to reproductive age-30\% more transgenic fish died within the first few days of development than the "wild" fish.

Using a computer model, Muir calculated that GM fish-bigger but less viable-could pass on inferior traits to a wild population. The transgenic growth hormone gene, there- fore, was dubbed the "trojan gene". His results showed 60 transgenic fish could lead to the extinction of a population of 60,000 fish in 40 generations. "This 'trojan gene' was one of the unexpected things we found," says Muir.

Moreover, Muir says the risk of GM fish escaping from aquaculture pens into the wild is a considerable one. Indeed, in Maine, home to a $\$ 65$ million salmon aquaculture industry, federal wildlife officials, environmentalists, and the aquaculture industry are battling against declining wild stocks of Atlantic salmon thanks in part to crossbreeding with escaped farm-raised fish of the same species. The farm-raised fish have trouble finding their way back to local streams to spawn and are diluting the wild stock, which has been proposed for adding to the federal endangered species list.

A/F Protein's Entis insists his fish don't die early and that Muir's study "has no relevance" to his commercial operation. In any case, Entis says his firm's fish eggs are sterilized and therefore would not pass on any inferior traits.

However, Muir notes that A/F Protein's sterilization technique - in which high pressure creates a triploidy instead of diploidy chromosomes in the developing egg-is not $100 \%$ reliable. "All you need is one egg," says
Muir. "We consider aquaculture the only place where biotechnology could have a risk in the environment."

The FDA, which is developing a model for the potential ecological risks of GM fish, would not comment on when A/F Protein's review will be complete.

Canadian government researchers are developing GM coho salmon and rainbow trout using a different transgene but methods similar to those of A/F Protein. Their studies on reproduction of the transgenic fish found that adult GM fish are 1.5 to 2 times larger than normal, even though they are raised in laboratory conditions. They feed more effectively but don't swim as well as their wild counterparts, according to Robert Devlin, chief scientist at the Department of Fisheries and Oceans in West Vancouver, BC.

Devlin says that very little data on survivorship of transgenic fish has been published, but agrees that the commercial production of such fish will depend on whether they can be made sterile. The answer may be to raise them on land rather than in ocean pens, for example. "Right now, people are making scare scenarios without any information," says Devlin. "We just need to be careful and move a bit slowly."

Eric Niiler

\section{Investigation of gene therapy begins}

The US Food and Drug Administration (FDA; Rockville, MD) and the National Institutes of Health (NIH; Bethesda, MD) have responded to widespread concerns about the risks of gene therapy with public meetings, reviews and investigations, and a series of administrative changes to deal with gene therapy more broadly. During December, members of the NIH Recombinant DNA Advisory Committee (NIHRAC), outside experts, NIH and FDA officials, and members of the news media and public met to review safety findings from both preclinical testing and gene therapy clinical trials. The meeting also provided a forum for airing renewed concerns about the effectiveness of federal oversight for such research, whose duties are shared by FDA and NIH.

The action follows the death last September of Jesse Gelsinger, an 18-year-old participant in a phase I gene therapy clinical trial at the University of Pennsylvania (UP; Philadelphia, PA) to evaluate the safety of a genetically engineered adenovirus vector (Nat. Biotechnol, 17, 1153). Gelsinger died following an acute respiratory system collapse and subsequent multiorgan failure, apparently brought on by a massive immune system response. Other unusual findings included severe damage to blood progenitor cells in the bone marrow, possibly due to a superimposed infection by another virus.

Current efforts to assess the safety of gene-therapy procedures are complicated because modified adenovirus-based vectors differ extensively from one another with respect to structural variability, differences in the way they are delivered to patients, and other differences that reflect the variety of transgenes that have been introduced into these vectors in efforts to treat various diseases.

The most recent version of the UP adenovirus vector has had several of its genes deleted, rendering it unable to replicate without a helper virus, according to its developers James Wilson and UP colleagues. Its general safety characteristics are good, based on animal tests, including in several strains of mice and primates. However, at high vector doses, some animals develop complications, including blood clotting abnormalities and mild to moderate liver damage, and several of them 